\title{
Out-of-hospital cardiac arrest due to coronary heart disease: a comparison of survival before and after the introduction of defribrillators in ambulances
}

\author{
Wilma S Leslie, Bridie Fitzpatrick, Caroline E Morrison, Graham C M Watt, \\ Hugh Tunstall-Pedoe
}

\begin{abstract}
Objective-To assess the actual impact on coronary mortality of equipping ambulances with defibrillators.

Design-Retrospective analysis of routine medical and legal records of all those who had a cardiac arrest attributed to coronary heart disease occurring outside hospital in a defined population before and after the introduction of Heartstart.

Setting-City of Glasgow, North of the River Clyde, 1984 and 1990.

Patients-296 and 267 men and women aged 25-64 inclusive in 1984 and 1990 respectively who had a cardiac arrest outside hospital which was attributed to coronary heart disease (International Classification of Diseases codes 410-414, ninth revision).

Results-The impact on coronary mortality in 1990 of equipping ambulances with defibrillators concurred with the earlier prediction of less than $1 \%$ of all coronary deaths. The circumstances of cardiac arrest were largely unchanged; most occurred outside hospital in the victim's home and the principal witnesses were members of the victim's family. A call for help before cardiac arrest was made in very few cases and cardiopulmonary resuscitation was attempted by laypersons in less than a third of the deaths they witnessed. There was a significant increase in the number of cardiopulmonary resuscitation attempts made by ambulance crews $(16 \% v 32 \%, P<0.01)$. Ambulance crews, however, still attended less than half of all cases (44\% and $47 \%$ ). Conclusion-The impact of equipping ambulances with defibrillators will remain small unless strategies are introduced that focus on improving the public's response to coronary emergencies by calling for help promptly and initiating cardiopulmonary resuscitation before the arrival of the emergency services.
\end{abstract}

(Heart 1996;75:195-199)

Keywords: defibrillation by ambulance crews; coronary death; cardiopulmonary resuscitation; delay times
Coronary mortality in Scotland is among the highest in the world. ${ }^{1}$ In North Glasgow, where all fatal and non-fatal coronary events have been monitored since 1984 as part of the World Health Organisation MONICA Project (multinational Monitoring of trends and determinants of Cardiovascular disease), ${ }^{2}$ men had the second highest and women the highest coronary mortality among participating centres. $^{3}$ The North Glasgow conurbation is a commercial centre which has seen a decline in heavy industry and there is high unemployment. It is an area of socioeconomic deprivation, $67 \%$ of the population lying within deprivation categories 6 and 7 (most deprived) as defined by Carstairs and Morris ${ }^{4}$ and updated by McLoone and Castairs (Scores for Scottish postcode sectors from the 1991 census. Glasgow: Public Health Research Unit, University of Glasgow; 1994) compared with $18 \%$ throughout Scotland.

Most coronary deaths occur outside hospital. ${ }^{56}$ In an attempt to reduce pre-hospital coronary mortality, Heartstart Scotland began in 1988 equipping all emergency ambulances with semiautomatic defibrillators and training crews in their use. ${ }^{7}$ This programme was complete by mid-1990. ${ }^{8}$

An earlier study using 1984 MONICA data predicted that equipping ambulances with defibrillators was unlikely to have a significant impact on coronary mortality unless there was a substantial increase in the proportion of patients who received medical attention before fatal collapse or bystander cardiopulmonary resuscitation, or both. ${ }^{5}$ The information collected by the Glasgow MONICA project since 1988 allows an evaluation to be made of the impact of the initiative on coronary mortality in North Glasgow.

The aims of this study were: (a) to evaluate the impact of Heartstart on coronary mortality in a defined population in 1990 by determining the number of lives saved in relation to the total number of out-of-hospital cardiac arrests attributed to coronary heart disease; (b) to investigate the circumstances of the deaths in order to determine which, if any, might be amenable to intervention; and (c) to determine whether there have been any changes in 
the public's response to coronary emergencies between 1984 and 1990.

\section{Patients and methods}

The study population consisted of all persons aged 25-64 years inclusive, resident in the city of Glasgow, North of the River Clyde. Patients with cardiac arrest attributed to coronary heart disease which occurred outside hospital were identified from data routinely notified to the Glasgow MONICA Project coronary event register. The main sources of case ascertainment were computerised hospital discharge data and deaths notified by the Registrar General for Scotland.

Patients in the present study were registered from these sources if they fulfilled the criteria for age and residency in the study population as defined by postcode, and if the diagnosis made at death or hospital discharge, or both, was classified within the range 410-414 of the International Classification of Diseases, ninth revision. Each registered patient was investigated by retrospective analysis of all available medical and legal records.

For the purposes of the present study additional data were included from the Heartstart project, comprising a computer listing of al patients in Glasgow in 1990 in whom defibrillation had been attempted by ambulance crews. Patients appearing on the Heartstart printout but not on the MONICA register were identified and cross referenced against the hospital discharge computer printout and Registrar General printouts for 1990. Patients in whom the diagnosis made at death or hospital discharge, or both, was other than coronary heart disease were not included in the present study.

As far as possible the methods employed in this study follow those of the earlier study. ${ }^{5}$ Accordingly, the present study was based on all patients with cardiac arrest attributed to heart disease and not solely those fulfilling WHO MONICA diagnostic criteria for definite or possible myocardial infarction, or those with insufficient data. Both studies therefore investigated more patients than those defined as myocardial infarction by the Glasgow MONICA register.

Each out-of-hospital cardiac arrest identified from the aforementioned sources was investigated to ascertain the previous medical history and the circumstances of the arrest including any attempts at intervention.

\section{Results}

A total of 267 cardiac arrests occurred outside

Table 1 Out-of-hospital cardiac arrests and coronary deaths in residents of North Glasgow (1984 and 1990)

\begin{tabular}{lcc}
\hline & 1990 & 1984 \\
\hline Population 25-64 years & 194149 & 198200 \\
Coronary deaths & 399 & 420 \\
Outside hospital & $263(66)$ & $296(70)$ \\
In hospital & $136(34)$ & $124(30)$ \\
Cardiac arrests outside hospital & 267 & 296 \\
Admitted to hospital & 4 & 0 \\
Survived to leave hospital & 2 & 0 \\
\hline Values in parentheses are percentages. &
\end{tabular}

Table 2 Place of coronary death outside hospital (1984 and 1990)

\begin{tabular}{lcc}
\hline Place of death & $\begin{array}{l}\text { No of cases } \\
\text { in } 1990\end{array}$ & $\begin{array}{l}\text { No of cases } \\
\text { in } 1984\end{array}$ \\
\hline Home & $203(77)$ & $215(73)$ \\
Public place & $27(10)$ & $43(15)$ \\
Private address & $15(6)$ & $14(5)$ \\
Work & $5(2)$ & $13(4)$ \\
En route to hospital in & $6(2)$ & $5(2)$ \\
$\quad$ Ambulance & $2(1)$ & $3(1)$ \\
$\quad$ Other transport & $5(2)$ & $3(1)$ \\
Not known & $263(100)$ & $296(100)$ \\
Total &
\end{tabular}

Values in parentheses are percentages.

hospital in 1990 (table 1) and were ascertained from the MONICA coronary register. No additional patients were identified from the records of Heartstart.

Some $73 \%$ of cardiac arrests occurred in men (mean age 56 years) and $27 \%$ in women (mean age 56 years). Two of the four people who responded to cardiopulmonary resuscitation by ambulance crews and were admitted to hospital survived to leave hospital. In view of the low survival from out-of-hospital cardiac arrest, the following analyses concentrate on the 263 deaths outside hospital.

\section{PLACE OF DEATH}

The 263 deaths in 1990 accounted for two thirds of all coronary deaths in the study population (table 1). There was no significant difference between 1984 and 1990 in the proportion of coronary deaths outside hospital. Most deaths still occurred at home (77\%) and few occurred in the workplace $(2 \%)$ and en route to hospital (3\%) (table 2 ).

\section{HISTORY OF CORONARY SYMPTOMS}

Direct comparison of the presence of symptoms before fatal collapse in 1984 and 1990 is not possible. Symptoms occurring immediately before fatal collapse were recorded in the present study, whereas symptoms occurring at any time in the previous 28 days were recorded in the 1984 study.

In 199031 deaths (12\%) were sudden, defined as having no preceding symptoms. Ninety four deaths $(36 \%)$ were preceded by symptoms, two thirds experiencing chest pain. It was not possible to determine whether any symptoms occurred before fatal collapse in 138 patients $(52 \%)$

Some $42 \%$ of patients had a history of coronary heart disease in 1990 and 1984 with almost half having had a previous myocardial infarction. Further analysis of the 1990 data shows that $41(44 \%)$ of the 94 patients who experienced symptoms had a history of coronary heart disease.

Table 3 Calls for help before and after fatal collapse (1984 and 1990)

\begin{tabular}{lcc}
\hline & $\begin{array}{l}\text { No of cases } \\
\text { in } 1990\end{array}$ & $\begin{array}{l}\text { No of cases } \\
\text { in } 1984\end{array}$ \\
\hline Call before fatal collapse & $41(16)^{\star}$ & $26(9)$ \\
Call after fatal collapse & $199(76)$ & $270(91)$ \\
Not known when call was made & $23(9)$ & 0 \\
Total & $263(100)$ & $296(100)$ \\
\hline Values in parentheses are percentages. ${ }^{\star} \mathrm{P}<0 \cdot 02, \chi^{2}$ squared \\
test.
\end{tabular}


Table 4 Relation of a previous history of coronary heart disease to the timing of the call for help in patients with known symptoms (1990)

\begin{tabular}{llll}
\hline & \multicolumn{2}{l}{ No of patients } & \\
\cline { 2 - 4 } Timing of the call for help & $\begin{array}{l}\text { History of coronary } \\
\text { heat disease }\end{array}$ & $\begin{array}{l}\text { No history of coronary } \\
\text { heart disease }\end{array}$ & Total \\
\hline Before fatal collapse & $17(41)$ & $24(45)$ & $41(44)$ \\
After fatal collapse & $24(59)$ & $29(55)$ & $53(56)$ \\
Total & $41(44)$ & $53(56)$ & $94(100)$ \\
\hline
\end{tabular}

Values in parentheses are percentages.

Table 5 Recipient of the initial call for help in relation to whether it was made before or after fatal collapse (1990)

\begin{tabular}{|c|c|c|c|c|c|c|}
\hline \multirow{2}{*}{$\begin{array}{l}\text { Timing of call } \\
\text { for help }\end{array}$} & \multicolumn{6}{|l|}{ No of cases } \\
\hline & Ambulance & GP/deputy & Police & Other ${ }^{\star}$ & Not known & Total \\
\hline $\begin{array}{l}\text { Before fatal } \\
\text { collapse } \\
\text { After fatal }\end{array}$ & $13(32)$ & $21(51)$ & $3(7)$ & $4(9)$ & 0 & $41(16)$ \\
\hline $\begin{array}{l}\text { collapse } \\
\text { Not known }\end{array}$ & $\begin{array}{l}70(35) \\
10(43)\end{array}$ & $\begin{array}{r}25(13) \\
3(13)\end{array}$ & $\begin{array}{c}55(28) \\
0\end{array}$ & $\begin{array}{c}27(13) \\
0\end{array}$ & $\begin{array}{l}22(11) \\
10(43)\end{array}$ & $\begin{array}{c}199(76) \\
23(9)\end{array}$ \\
\hline Total & $93(35)$ & $49(19)$ & $58(22)$ & $31(12)$ & $32(12)$ & $263(100)$ \\
\hline
\end{tabular}

Values in parentheses are percentages. ${ }^{\star}$ Includes relatives, friends, and neighbours. GP, general practitioner.

Table 6 Number of cardiopulmonary resuscitation (CPR) attempts by persons witnessing death (1984 and 1990)

\begin{tabular}{|c|c|c|c|c|}
\hline \multirow[b]{2}{*}{ Witness } & \multicolumn{2}{|l|}{1990} & \multicolumn{2}{|l|}{1984} \\
\hline & $\begin{array}{l}\text { No of } \\
\text { deaths }\end{array}$ & $\begin{array}{l}\text { No of } C P R \\
\text { attempts }\end{array}$ & $\begin{array}{l}\text { No of } \\
\text { deaths }\end{array}$ & $\begin{array}{l}\text { No of } C P R \\
\text { attempts }\end{array}$ \\
\hline Spouse & $36(14)$ & 5 & $47(16)$ & 4 \\
\hline Other family member & $24(9)$ & 10 & $25(9)$ & 6 \\
\hline Bystander & $12(5)$ & 5 & 33 (11) & 17 \\
\hline Neighbour & $7(3)$ & 3 & $15(5)$ & 6 \\
\hline GP/deputy & $9(3)$ & $12^{\star}$ & $4(1)$ & 1 \\
\hline Ambulance crew & 7 (3) & $40^{\star} \dagger$ & $4(1)$ & $21^{\star}$ \\
\hline Police & 2 & 1 & 1 & 3 \\
\hline Persons unknown & $4(2)$ & 0 & $10(3)$ & 0 \\
\hline No witness & $148(56)$ & 0 & $119(40)$ & 0 \\
\hline \multirow{2}{*}{$\begin{array}{l}\text { Not known whether } \\
\text { witnessed }\end{array}$} & & & & \\
\hline & $14(5)$ & 0 & $38(13)$ & 0 \\
\hline Total & $263(100)$ & 76 & $296(100)$ & 58 \\
\hline
\end{tabular}

Values in parentheses are percentages. ${ }^{\star}$ Number of CPR attempts greater than number of deaths witnessed because in some events those who first attempted CPR arrived at the scene after fatal collapse had occurred. $+\mathrm{P}<0.01, \chi^{2}$ squared test. GP, general practitioner.

CALL FOR HELP

The call for medical attention was not made until after fatal collapse in most patients in both years (table 3 ). However, more calls were made before the fatal collapse in 1990 than in $1984(16 \% v 9 \%, \mathrm{P}<0.02)$. Further analysis of patients with symptoms before fatal collapse in 1990 showed no significant difference between those with and without a history of coronary heart disease in relation to seeking help (table 4).

In 1990 the initial call for help was made to the ambulance service in only 93 cases (35\%); there was no difference in the proportion of calls made before or after fatal collapse (table 5). Most calls before fatal collapse were to general practitioners ( $51 \%$ ); only $7 \%$ summoned the police. General practitioners were first to be contacted after fatal collapse in $13 \%$ of cases, while the police were contacted in $28 \%$.

Ambulance crews attended less than half of all coronary deaths in the community in both 1990 and $1984,47 \%$ (124) and 44\% (130) respectively.

\section{WITNESSES AND CARDIOPULMONARY} RESUSCITATION ATTEMPTS

Fewer deaths were witnessed in 1990 than in $1984(101(38 \%) v 139(47 \%)$. In both years the principal witness was most often a member of the victim's immediate family (table 6). Although the proportion of deaths witnessed by ambulance crews and general practitioners increased in 1990, the increase was small and did not achieve statistical significance.

Between 1984 and 1990 there was no significant change in the number of cardiopulmonary resuscitation attempts by lay persons. In the cases they attended ambulance crews were twice as likely to attempt cardiopulmonary resuscitation in $1990(32 \% v 16 \%$, $\mathrm{P}<0.01$ ).

\section{Discussion}

Heartstart had little impact on coronary mortality in North Glasgow in 1990. Four people survived cardiac arrest in the community and only two of these survived to leave hospital. These survivors represent less than $1 \%$ of all coronary deaths under the age of 65 in the study population. This finding concurs with the predicted impact of equipping ambulances with defibrillators on the coronary mortality of this population ${ }^{5}$ and is significantly less than the $10 \%$ survival in patients attended by ambulance throughout Scotland reported by Heartstart. $^{8}$

Comparison between studies that examine survival from out-of-hospital cardiac arrest is difficult. Numerators and denominators may not be consistent between studies resulting in survival rates that are hard to compare. ${ }^{9}$ The present study included only patients aged under 65 in whom the underlying cause of cardiac arrest was coronary heart disease, and to assess the impact of equipping ambulances with defibrillators on coronary mortality expressed the survivors as a percentage of the total number of coronary deaths in a defined population. By contrast, Heartstart used as the denominator all patients attended by ambulance crews regardless of cause throughout Scotland. Heartstart results reflect survival only in those patients attended by ambulance crews and cannot be interpreted as a $10 \%$ reduction in coronary mortality. Similarly, a later study carried out in Glasgow Royal Infirmary, ${ }^{10}$ which identified 13 survivors from out-of-hospital cardiac arrest, used patients seen in the emergency department regardless of age, cause, and place of residence as the denominator. When the difference in denominators is accounted for only four of these patients would fulfil the criteria for inclusion in the present study.

The American Heart Association ${ }^{11}$ emphasises the concept of the "chain of survival" in the outcome of sudden cardiac arrest, defining the links in this chain as: (a) early access which includes recognition of symptoms/cardiac arrest and activation of emergency services; (b) early cardiopulmonary resuscitation; (c) early defibrillation; and (d) early advanced care. 
While different strategies are required to develop and establish each link, survival from sudden cardiac arrest is more likely if the links are activated in sequence. Absence of, or weakness in, any link lessens the chance of survival and "condemns the emergency services to poor results". ${ }^{11}$

By examining the circumstances of cardiac arrests outside hospital in Glasgow in relation to the links in the chain of survival and experiences elsewhere, we can identify local strategies which may have an impact on coronary mortality.

\section{EARLY ACCESS}

\section{Recognition of symptoms}

While significantly more people called for help before fatal collapse in 1990 than in 1984, most calls were delayed until after fatal collapse. We are unable to distinguish those who failed to recognise symptoms from those who did but were reluctant to call for medical help. It is likely that the delay in calling for help is due to both factors since evidence from this study and others indicates that a previous history of coronary heart disease does not influence the decision to call for help. ${ }^{12} 13$

Public delay in calling for help has been identified consistently as the most significant factor in the delay from onset of symptoms to definitive coronary care. ${ }^{13} 14$ Campaigns to reduce the delay in calling for help have achieved varying success. In King County Washington, a multimedia campaign to educate the public to recognise coronary symptoms and the importance of calling the emergency service promptly achieved no significant reduction in delay. ${ }^{15} \mathrm{~A}$ similar campaign in Sweden reduced the median delay to arrival at hospital from $3 \mathrm{~h}$ to $2 \mathrm{~h} 40 \mathrm{~min}$ utes. ${ }^{16}$

The British Heart Foundation's guidelines for the early management of myocardial infarction $^{17}$ suggest targeting education at those with known coronary heart disease and their families. There is a strong argument for adopting this approach in Glasgow. About half of the patients who experienced symptoms before fatal collapse had a previous history of coronary heart disease and most fatalities occurred in the victim's home in the presence of family members. If these guidelines had been in place in 1990, this approach may have prompted a swifter response to coronary symptoms in 41 patients, representing $16 \%$ of all community deaths. It may have resulted in help being sought before fatal collapse in 24 of these patients. Education campaigns should focus on individuals known to be at high risk and their families and include instruction on how to distinguish angina from an acute coronary event. Patients and family members should understand that denial is a normal but inappropriate response to acute coronary symptoms. Cardiac rehabilitation programmes are an ideal starting point for such education, but the message needs to be reinforced by general practitioners, practice nurses, or extended cardiac rehabilitation programmes.

\section{Activation of emergency services}

Most calls before fatal collapse in 1990 were made to general practitioners, while only one third was made to the ambulance service. Another study in Glasgow has shown that the delay in arrival at hospital was 75 min longer in patients referred by general practitioners than self-referrals. ${ }^{13}$

Persuading the public to contact the ambulance service in preference to their general practitioner, however, is difficult to achieve. While some education campaigns have succeeded in reducing the delay by people who call for help, they report no success in increasing the proportion of people who call the ambulance service in the first instance. ${ }^{15} 18$

While the public remain resistant to such advice, general practitioners should be encouraged to request the attendance of an ambulance before travelling to attend patients with a suspected coronary emergency. It may also be worthwhile for the ambulance service to publicise that they will respond to calls from the public.

The ambulance service appreciates the need to respond quickly to coronary emergencies but a rapid response in city areas can be hampered by heavy traffic. Since 1990, however, response times in Glasgow have improved steadily. Scottish ambulance statistics for April to September 1994 show that $39 \%$ of emergency calls are attended within seven minutes (Orcon target 50\%; Operational Research, developed by Cranfield Institute of Technology; used nationally to measure ambulance activation and response times) and $90 \%$ within 14 minutes (Orcon target 95\%), compared with $31 \%$ and $18 \%$ respectively in 1991 (H. Newton personal communication, 1994).

EARLY CARDIOPULMONARY RESUSCITATION

Cardiopulmonary resuscitation is attempted infrequently by witnesses of cardiac arrest in Glasgow. Attempts were made only in one third of cardiac arrests witnessed by laypersons in 1990; a figure unchanged from 1984. Family members, the most common known witnesses, were least likely to attempt cardiopulmonary resuscitation.

Recent market research has identified possible explanations for the low incidence of cardiopulmonary resuscitation attempted by bystanders (System Three Scotland, unpublished data, 1994). Respondents included members of the general public and carers of those with coronary heart disease. While some carers said that attempting cardiopulmonary resuscitation would not occur to them, both groups admitted that they were afraid of doing more harm than good by attempting cardiopulmonary resuscitation. Furthermore, respondents expressed reluctance to initiate cardiopulmonary resuscitation on a stranger for fear of infection, particularly human immunodeficiency virus, and in case it was an inappropriate action.

While learning about resuscitation was considered worthwhile, many people admitted that they would be unlikely to attend a training course. Lack of motivation and a reluctance to 
use personal time and money were some of the reasons cited. Training provided in the workplace, schools, and colleges may overcome some of these obstacles. Cardiopulmonary resuscitation in schools is strongly advocated in the Scottish Health Service Advisory Council's report on cardiopulmonary resuscitation. ${ }^{19}$

Targeting the families of middle aged people or those with a history of myocardial infarction is an alternative approach to cardiopulmonary resuscitation training. ${ }^{11} 19$ Carers were in general more willing to receive cardiopulmonary resuscitation training (System Three Scotland, unpublished data, 1994). Our findings suggest that the maximum impact of the latter approach in 1984 would have been to provide cardiopulmonary resuscitation in $4 \%$ of community deaths. In 199019 of 51 patients with a history of myocardial infarction had an arrest in the presence of a family member, cardiopulmonary resuscitation was attempted in only four. A cardiopulmonary resuscitation training campaign targeted at carers may have prompted attempts at resuscitation in 15 patients, representing $6 \%$ of all community deaths.

Our data suggest that targeting the families of middle aged men may have a greater impact. Of 42 male deaths witnessed by a family member in 1990, attempts at resuscitation were made in only 12 . A targeted campaign may have prompted attempts at resuscitation in 30 patients, representing $11 \%$ of all community coronary deaths.

\section{EARLY DEFIBRILLATION}

The provision of early defibrillation in Glasgow is dependent on the attendance of ambulance crews. Less than half of all patients with cardiac arrest in the community were attended by the ambulance service in 1984 and 1990; a situation not unique to Glasgow. ${ }^{20}$ The initial call for help in one fifth of patients with cardiac arrest was to the police and these victims were probably beyond treatment. Taking these patients into consideration, however, there is still about one third who may have derived benefit from ambulance crews equipped with defibrillators.

\section{EARLY ADVANCED LIFE SUPPORT}

Advanced life support by ambulance crews, providing intubation and administration of cardiac drugs, was not available in 1990. A second tier of paramedics trained in these skills has since been introduced to the service. Just over half of all emergency ambulance crews in Glasgow now includes a paramedic, and recruitment is continuing ( $\mathrm{H}$ Newton, personal communication, 1994). Such developments elsewhere have reported improved survival from sudden coronary death. ${ }^{11}$

Efforts to reduce pre-hospital coronary mortality in Glasgow have focused on the latter two links in the chain of survival, namely early defibrillation and early advanced care. The impact of Heartstart on coronary mortality in Glasgow will remain small without more vigorous attention to the early access and early cardiopulmonary resuscitation links.

The authors would like to acknowledge the help given by Haydon Newton, Operation Director, Scottish Ambulance Service. Scottish MONICA is supported by the Chief Scientis Office, Scottish Home and Health Department. The discussion and conclusions of the paper are the responsibility of the authors and do not necessarily reflect the views of the Scottish Home and Health Department.

1 Uemara K, Pisa Z. Trends in cardiovascular disease mortality in industrialised countries since 1950. World Healt Stat $Q 1988 ;$ No $3 / 4: 155-78$.

2 WHO MONICA Project principal investigators prepared by Tunstall-Pedoe $\mathrm{H}$. The World Health Organisation MONICA Project (monitoring trends and determinants in cardiovascular disease): a major international collaboration. $\mathcal{F}$ Clin Epidemiol 1988;41/2:105-14.

3 WHO MONICA Project prepared by Tunstall-Pedoe $\mathrm{H}$, Kuulasma K, Amouyel MD, Arveiler D, Rajakangas A, Pajak A Mymoling Pajak A. Myocardial infarction and coronary deaths in the WHO MONICA Project: registration procedures, event rates and case fatality rates in 38 populations from 21 countries

4 Carstairs V, Morris R. Deprivation and health in Scotland. Aberdeen: Aberdeen University Press, 1991

5 Fitzpatrick B, Watt GCM, Tunstall-Pedoe H. Potential impact of emergency intervention on sudden deaths from coronary heart disease in Glasgow. Br Heart $\mathcal{f} 1992 ; 67$ $250-4$

6 McNeilly RH, Pemberton J. Duration of last attack in 998 fatal cases of coronary artery disease and its relation to possible cardiac resuscitation. BMF 1968;3:139-42.

7 Cobbe SM, Redmond MJ, Watson JM, Hollingworth J, Carrington DJ. "Heartstart Scotland"-initial experience of a national scheme for out of hospital defibrillation. $B M \mathcal{F}$ 1991;302:1517-20.

8 Sedgwick ML, Dalziel K, Watson J, Carrington DJ, Cobbe SM. Performance of an established system of first responder out-of-hospital defibrillation. The results of the second year of the Heartstart Scotland Project in the "Ustein style". Resuscitation 1993;26:75-88.

9 Valenzuela TD, Spaite DW, Meislin HW, Clark LL, Wright AL, Ewy GA. Case and survival definitions in out-of-hospital cardiac arrest. Effect on survival rate calout-of-hospital cardiac arrest. Effec
culation. $\mathcal{F} A M A$ 1992;26:272-4.

10 Rainer TH, Gordon MWG, Robertson CE, Cusack S Evaluation of outcome following cardiac arrest in patients presenting to two Scottish emergency departments Resuscitation 1995;2:33-9.

11 Advanced Cardiac Life Support Subcommittee and Emergency Cardiac Care Committee, American Heart Association. Improving survival from sudden cardiac arrest: the "chain of survival" concept. Circulation 1991; 83:1832-47.

12 Rawles JM, Haites NE. Patient and general practitioner delays in acute myocardial infarction. $B M \mathcal{F} 1988 ; 296$ : $882-4$

13 Wallbridge DR, Tweddel AC, Martin W, Cobbe SM. The potential impact of patient self referral on mortality in acute myocardial infarction. $O f \mathrm{Med} 1992$; new series8 $(307-8): 909-9$.

14 Armstrong A, Duncan B, Oliver MF, Julian DG, Donald $\mathrm{KW}$, Fulton $\mathrm{M}$, et al. Natural history of acute coronary heart attacks. A community study. Br Heart $\mathcal{f} 1972 ; 34$ : heart a

15 Ho MT, Eisenberg MS, Litwin PE, Schaffer SM, Damon SK. Delay between onset of chest pain and seeking medical care: the effect of public education. Ann Emerg Med ical care: the effect

16 Blohm M, Herlitz J, Hartford M, Karlson W, Risenfors M, Russell V, et al. Consequences of a media campaign focusing on delay in acute myocardial infarction. $A m \mathcal{F}$ Cardiol 1992;69(4):411-3

17 Weston CFM, Penny WJ, Julian DG on behalf of the British Heart Foundation Working Group. Guidelines for the early management of patients with myocardial infarction. $B M \Im$ 1994;308:767-71.

18 Herlitz J, Hartford M, Blohm M, Karlson W, Ekstrom L Risenfors M, et al. Effect of a media campaign on delay times and ambulance use in suspected acute myocardial infarction. Am $\mathcal{F}$ Cardiol 1989;64:90-3.

19 Scottish Health Service Advisory Council. Report of the working group on cardiopulmonary resuscitation (CPR). Edinburgh: HMSO, June 1992, updated July 1993.

20 Rowley JM, Garner C, Hampton JR. The limited potential of special ambulance services in the management of cardiac arrest. Br Heart $\mathcal{F}$ 1990;64:309-12. 